\title{
LINQUISTIC PROFICIENCY AND ITS APPLICATION TO ART CRITICISM AND ART APPRECIATION
}

\section{Candace Jesse Stout}

Recent trends in art education involve the students in the process of responding to art. Chapman (1978) sees this procedure as being as "complex and demanding as is the process of creating" and as "worthy of the same attention and educational time...." (p. 64). Hamblen (1984) and Feldman (1978) also support the premise that art criticism and art appreciation offer rigorous academic challenges. Meticulous observation and description, careful analysis and interpretation, and ultimate synthesis and evaluation require the highest levels of Bloom's taxonomy (Hamblen, 1984). Because of the cognitive approach in teaching response to art objects, educators in all major disciplines are beginning to recognize what art educators have long purported: there is inherent scholastic value in art education. Our professional literature abounds in studies advocating a discipline-based approach, a strong, carefully-sequenced knowledge base. Moreover, journals now feature articles promoting interdisciplinary or integrated approaches, thus pairing the visual arts with other academic subject areas [see Art Education, 1985, 38 (6)]. Nine years ago, Elliot Eisner questioned, "To what extent, if any, does work in the arts develop forms of cognition that affect competencies in areas outside the arts?" (1977, p. 25). Inversely, it is equally important to ask to what extent, if any, does work in other disciplines develop or enhance proficiency within the visual arts? It is established that study in mathematics and sciences mutually compliment one another. Such "givens" must also be established within the visual arts so that curriculum can be devised and structured accordingly.

Central among these cross-disciplinary studies involving visual art and other academic areas should be research concerning linguistic competence. Many art educators (Johansen, 1981; Onofrio and Nodine, 1981; Chapman, 1978; Feldman, 1970; Lankford, 1984; Hamblen, 1984) assert that the 
success of any art appreciation/art criticism lesson hinges upon lively, relevant, carefully structured linguistic interchange, in short, an interactive dialogic approach. Although some insist that it must be oral, others just as enthusiastically promote "paper talk" about art objects, rich and expressive writing responses to art (Thoms, 1985); these, too, are dialogic. Whether it is written or oral, a strong case has been made for linguistic interchange about art objects in order for understanding and consequential appreciation to be fully realized.

All this leads to the premise that there is a need for linguistic proficiency, a sophisticated command of language skills, in order for the observer to organize, structure, and effectively relate to formal and expressive nuances he/she perceives within an art work (Harris, 1963). This study examines the relationships between language proficiency and the ability to discern expressive and formalistic qualities in paintings.

Related studies in this realm deal with three basic areas. There is, for example, a body of research which deals with the transference of skills learned in art criticism to those which are conducive to reading readiness (Smith, 1983, Feldman, 1978). Studies which concentrate on the use of the visual arts as writing stimuli are abundant (Comprone, 1973; Rothmel, 1977; Thoms, 1985; Wang, 1973). Another prolific area of research has explored visual and language arts in conjunction with abstract reasoning, cognitive processes, concept formation, and visual perception (Arnheim, 1971; Church, 1983). Closest to the present study are several which examine the relationships between spoken language and drawn images. In his studies which show that children's concepts are strongly influenced by language acquisition and proficiency, Harris (1963) corroborates the need for linguistic mastery in the visual arts. Further, Willats (1977) found that there is a positive correlation between drawing ability and language acquisition; sophistication in drawing technique increased with age as did linguistic sophistication. Finally, Colbert's (1984) study found a positive correlation between age and its effect upon language skills and drawing.

In the subject's verbal and drawn responses, their sophistica- 
tion of denotation increased with age. More specific

words, phrases, and symbols were most often used by

older subjects to denote qualities of the model. (p. 88)

Based upon the findings of her study, Colbert also stated that "children's individual descriptive abilities show a relationship between language and drawing symbolic systems" (p.90), a concept most closely related to the present research.

The null hypothesis to be tested in this study maintains that there is no relationship between linguistic competence (in English) and the ability to describe, analyze, interpret and evaluate art works.

\section{Method}

\section{Subjects}

Sixty-six subjects from a large mid-western university participated in this study. All were students currently enrolled in an introductory art appreciation class under the same instructor. Although the majority were freshmen and sophomores, there were also juniors and seniors among the population.

\section{Test Materials and Procedure}

The results of two different tests were utilized. The first was a 40minute standardized college entrance English examination (CET) which consisted of three parts totaling 90 items. Every entering college freshman is required to take this test under structured testing circumstances. The first part is designed to test mechanical know-how (capitalization, grammar, punctuation, and spelling). Not only is acquired knowledge tested here, but meticulous observation, coupled with the ability to apply previous knowledge and skills to a novel situation, are also imperative in order to detect mechanical or structural anomalies. Parts II and III require the student to decide which, among four groups of sentences, expresses an idea efficiently and effectively, and then ask for a sequential ordering of ideas and an ability for logical structuring of parts (sentences) to yield an expressive holistic concept.

The second test given to the same group of 66 subjects consisted of 
17 color slides of master paintings, none of which had been shown before in this class. Subjects were broken into two groups and were shown slides on a screen in the classroom wherein they regularly attended class. Students were given a sheet of 17 multiple choice items (each consisting of four choices per slide) and were asked to choose which descriptor was most closely applicable to each painting. Each slide was projected for a duration of two minutes. Choices pertained to both formalistic and expressive qualities of the paintings, ranging from general concepts of style to symbolic content. In order to set a standard for the expected responses, five art educators were first given the same test; the results of each item showed a consensus which established validity for responses required of the students.

\section{Results and Discussion}

The subjects' results from the standardized English test were obtained from the University Testing Service for purposes of comparison with their performance on the art analysis test. Scoring on the art test was based on one point for a correct response and a 0 for an incorrect response. Each subject made 17 responses, which gave a possible score range from 0 to 17 .

In order to obtain an index of the linear relation between the two variables (scores on the language proficiency test and scores on the art analysis test), the Pearson product-moment correlation coefficient (Jurs, 1982) was determined. With a degree of freedom equal to 64 , the resulting correlation coefficient of .302 is significantly different from 0 ( $p<.05)$. This means, then, that the higher the students scored on the CET, the better they performed on the art analysis test.

Next, the paired samples were broken into two groups: those that scored above the 70th percentile on the CET and those that scored below. A $T$ test of the difference between the means of paired samples (Sokal and Rohlf, 1969) was performed on the two groups of art scores. This test showed that the means of the two groups are significantly different, with $P$ being between .01 and .005 . The group which scored higher (above $\mathrm{P}_{70}$ ) on the language skills test had a significantly higher mean on the art 
analysis test than the group with lower language proficiency scores (see Table).

Table

Sample and Test Statistics

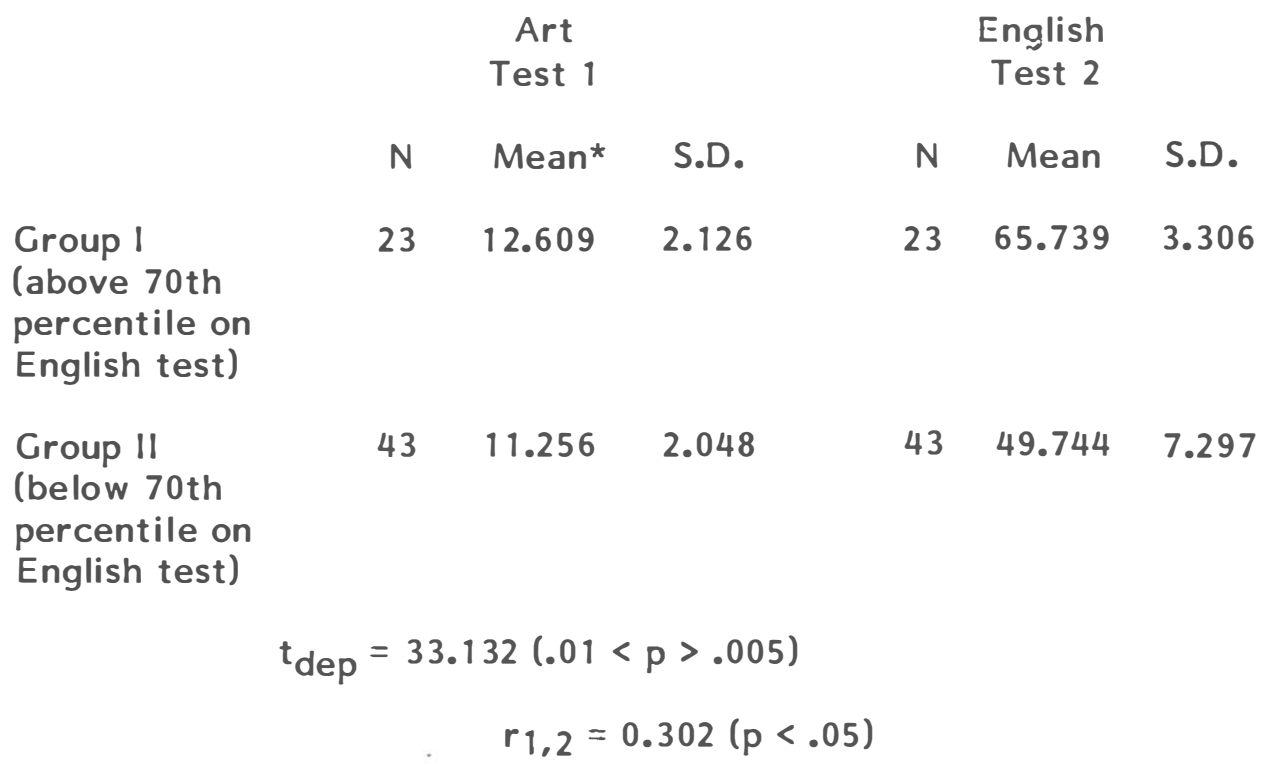

\section{Conclusions}

Thus, based upon the Pearson $r$ and the $T$ test, the null hypothesis would be rejected. The research at this level, therefore, suggests that those skills required for complex and sophisticated language mastery parallel those requisites for successful art criticism and art appreciation. Astute observation, analytical and interpretive skills and ultimate evaluation all require decisions concerning individual structural units (in language, morphology, phonology and syntax; in painting, the basic visual elements, e.g., line, color, texture, shape, etc.). Proficiency in both require the ability to structure and sequence, coupled with an ultimate understanding of coherence and unity of parts which produce an expressive whole.

Because of the multi-faceted nature of the visual arts, interdisciplinary research in this area should be emphasized. This study serves only as a seed for inchoate correlation between linquistics and the visual arts. 
There are many other variables which must be considered, such as foreign language training and proficiency. The two tests utilized here are general in nature, testing broad linguistic and artistic concepts. Further studies which involve more intensive written and oral examination with more finely discriminating factors must be administered and analyzed.

\section{REFERENCES}

Arnheim, R. (1969). Visual thinking. Berkeley: University of California Press.

Chapman, L. (1978). Approaches to art in education. New York: Harcourt Brace Jovanovich, Inc. (64-91).

Church, V. (1983). Comparison of the unique and common processing hypotheses in picture and word memory. Doctoral dissertation, Emory University.

Clark, G., $\varepsilon$ Lewis, H. (Eds.). (1985). Mini-Issue: Integrated art education. Art Education, 38 (6).

Colbert, C. (1984). The relationship of language and drawing in description and memory tasks. Studies in Art Education, 25 (2), 84-91.

Comprone, J. (1973). Using painting, photography and film to teach narration. College English, 35 (2), 174-178.

Eisner, E. (1977). Thoughts on an agenda for research and development in arts education. In S. Madeja (Ed.), Arts and aesthetics: An agenda for the future (pp. 17-30). St. Louis: CEMREL.

Feldman, E. (1970). Engaging art in dialogue. In G. Pappas (Ed.), Concepts in art education (pp. 352-360). London: The MacMillan Company.

Feldman, E. (1978). Art, criticism, reading. In E. Eisner (Ed.), Reading, the arts, and the creation of meaning (pp. 141-157). National Art Education Association.

Hamblen, K. (1984). An art criticism questioning strategy within the framework of Bloom's Taxonomy. Studies in Art Education, 26 (1), 41-50.

Harris, D. (1963). Children's drawings as measures of intellectual 
maturity. New York: Harcourt, Brace $\varepsilon$ World, Inc.

Johanse, P. (1981). A model for teaching art appreciation. In G. Hardiman

$\varepsilon$ T. Zernich (Eds.), Review of research in visual arts education, 13

(pp. 64-76). Champaign, IL: University of Illinois.

Johansen, P. (1982). Teaching artistic discerning through dialog. Studies

in Art Education, 23 (2), 6-13.

Jurs, Hinkle, W. (1982). Basic behavioral statistics. Boston, MA:

Houghton Mifflin Company.

Lankford, L. (1984). A phenomenological methodology for art criticism.

Studies in Art Education, 25 (3), 151-158.

Onofrio, A., $\varepsilon$ Nodine, C. F. (1981). Children's responses to paintings.

Studies in Art Education, 23 (1), 14-23.

Rothmel, S. (1977). A picture can generate a thousand words. Exercise

Exchange, 21 (2), 3-4.

Smith, N. (1983). Art criticism and reading: Theoretical and psychological

foundations. Doctoral dissertation, University of Georgia.

Sokal, R., \& Rohlf, J. (1969). Biometry. San Francisco: W. H. Freeman

and Company.

Thoms, H. (1985). Multiple views of a painting. Art Education, 38 (6), 10-12.

Wang, M. (1973). Verbal prompting and young children's descriptive language. Language Sciences, 25, 27-31.

Willats, J. (1977). How children learn to represent three-dimensional space in drawings. In George Butterworth (Ed.), The child's representation of the world. New York: Plenum Press. 